\title{
A Review of The Properties of The Pulmonary Artery in Pulmonary Arterial Hypertension with Emphasis on The Water Hammer
}

\author{
Sinanis $\mathrm{T}^{* 1}$ and Igglezakis $\mathrm{D}^{2}$ \\ ${ }^{1}$ Department of cardiology, Greece \\ ${ }^{2}$ Department of Production and management engineering, Greece \\ *Corresponding author: Sinanis T, Department of cardiology, chania general hospital, greece
}

\section{ARTICLE INFO}

Received: 慧 November 18, 2019

Published: December 02, 2019

Citation: Sinanis T, Igglezakis D. A Review of The Properties of The Pulmonary Artery in Pulmonary Arterial Hypertension with Emphasis on The Water Hammer. Biomed J Sci \& Tech Res 23(3)-2019. BJSTR. MS.ID.003890.

\begin{abstract}
Pulmonary hypertension is defined as resting average pressure, measured with a right heart catheter, in the pulmonary artery $\geq 25 \mathrm{mmHg}$. A known phenomenon that occurs in every pump system with rapid change in flow (due to valve opening and closing) is the Water Hammer. A correlation between the water hammer phenomenon, the arterial stiffness and as a result the elasticity of the arterial wall has already been proven. Due to the viscoelastic nature of the human arteries, the increased stiffness of the pulmonary artery in patients with pulmonary hypertension the presence of the water hammer cannot be excluded. The methods of its encounter in engineering are here presenting, suggesting an alternative for future perspectives in the treatment of pulmonary hypertension.
\end{abstract}

Abbreviations: PC: Pulmonary Capillary Wedge Pressure, ESC: European Society of Cardiology, PVR: Pulmonary Vascular Resistance, PAM: Average Pulmonary Artery Pressure, CO: Cardiac Output

\section{Introduction}

\section{Definition of Pulmonary Hypertension}

Pulmonary hypertension is defined as resting average pressure, measured with a right heart catheter, in the pulmonary artery $\geq 25 \mathrm{mmHg}$ [1]. According to the current data situation, normal average pressure in the pulmonary artery has a maximum value of $20 \mathrm{mmHg}$ [2]. Patients with values between 21 and $24 \mathrm{mmHg}$ (= Borderline pulmonary hypertension) should, according to the most recent guidelines of the [3] European Society of Cardiology (ESC), not be treated. Regular check-ups are, however, necessary. The diagnosis of pulmonary hypertension can only be made using resting measurements, earlier definitions such as "load-induced pulmonary hypertension" are no longer valid, according to the newest studies [4]. Depending on Pulmonary Capillary Wedge Pressure (PC) and Pulmonary Vascular Resistance (PVR), different hemodynamic definitions of pulmonary hypertension exist, with corresponding clinical symptoms [5].

\section{Pulmonary Artery Compliance (CPA)}

The transfer of pressure through the entire circulation and control of blood flow are necessary preconditions for the development of pulmonary circulation. For these tasks to be fulfilled optimally and taking into account the normally low pressure in the pulmonary circulation, the pulmonary arteries must normally show high elasticity (compliance) [6]. The relationship between pressure and volume, called volume elasticity or arterial compliance, is used to describe this issue. This is usually defined by the quotient:

Compliance $(\mathrm{C})=($ stroke volume $) /($ pulse pressure $)=\mathrm{SV} / \mathrm{PP}$ (I),

where: pulse pressure $=$ systolic pressure minus diastolic pressure .

This calculates the blood volume that can be accommodated in a vessel, with a predefined diameter, at a known pressure. An 
artery with high compliance, is called an elastic artery, one with low compliance, is a stiff artery $[7,8]$. The importance of compliance lies in the fact that an artery with high compliance can store a relatively large quantity of the blood expelled from the ventricle during the systole and then release this volume in the diastole, so that there is a continuous flow into the pulmonary circulation [9]. Arteries with low compliance do not have this ability and their contribution to the diastolic flow is small [6,7]. Compliance was already an essential element of the two-element model [10] in the first description of the arterial air-vessel (windkessel) in the year 1899 and was also used in the three [11] and four-element windkessel model [10]. These descriptions tried to explain how the arterial system worked. The air-vessel model of the pulmonary circulation is based on the function of a fire brigade air-vessel (Figures 1 \& 2). The pump (heart) conveys the water (blood) to the air vessel (elastic artery). The compressed air in the air vesssel was a storage function (compliance) which makes it possible to distribute the water faster and with higher pressure.

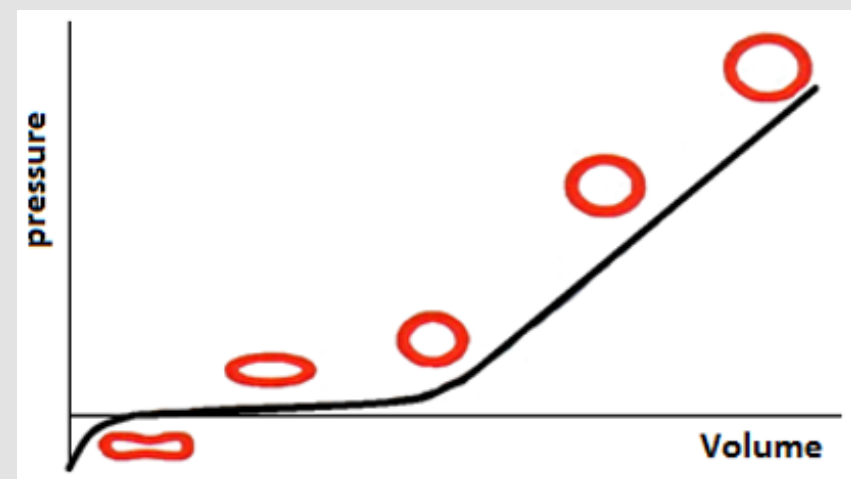

Figure 1: Pressure-volume relationship and example of the vascular reaction to different compliance. As the vessel is filled, the cross-sectional shape of the vessel changes from oval to round. Reprint by courtesy of [8].

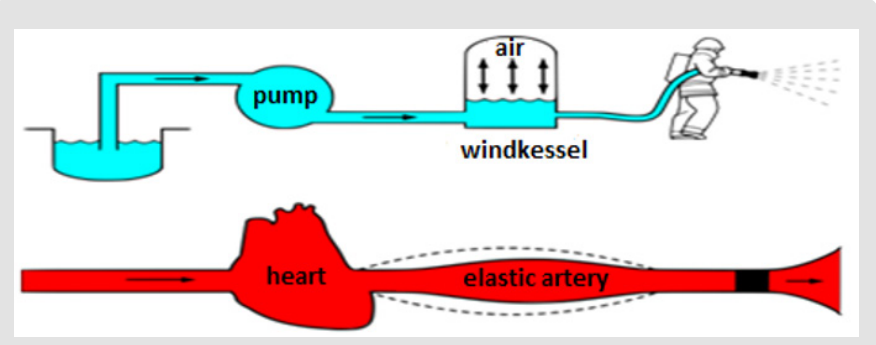

Figure 2: Comparison between the windkessel phenomenon in the cardiovascular system and the fire brigade's air-vessel. Reprint by courtesy of [6].

The change in compliance in PAH is a more decisive factor in the development of the prognosis and the treatment of the patients. There are clinical $[11,12]$ and experimental [13] indications that the reduction in compliance is a decisive parameter in the multifactorial genesis of the disease. The reduction occurs simultaneously with the increase in PVR [7]. Therefore, in contrast to the other vascular property's compliance is always reduced in patients with $\mathrm{PAH}$, irrespective of the etiology of the PAH [14]. In order to understand the independent role of compliance better, Sajanet (15) examined its relationship to the clinical evaluation and the symptoms of PAH. They discovered that a reduction in compliance accompanies the increase of various hemodynamic parameters (PAm, PVR, RApressure) and a worsening of resilience (shorter distance walked in the 6-minute walk test), as well as being associated with an increased likelihood of an inpatient stay [15]. An increase in compliance can be achieved as a signof a hemodynamic improvement. Specialized drug therapy with bosentan and sildenafil leads to an improvement in the SV/PP ratio in PAH patients, together with an increase in resilience [16].

\section{Pulmonary Vascular Resistance (PVR)}

Vascular resistance is a quantitative description of the relationship between the pressure difference along the vessel and the blood flow [6]. Although the resistance can be calculated with Poiseuille's law, Ohm's law is used in daily clinical practice [17]:

$$
R=\frac{\Delta P}{Q}
$$

Where: $\mathrm{R}=$ resistance, $\Delta \mathrm{P}=$ pressure difference, $\mathrm{Q}=$ blood flow.

The result of applying this law for the pulmonary circulation, is the equation for pulmonary vascular resistance:

$$
\mathrm{PVR}=\frac{\mathrm{pAm}-\mathrm{pc}}{C O}
$$

Where: PVR = Pulmonary Vascular Resistance, $\mathrm{PAM}=$ Average Pulmonary Artery Pressure, PC = Pulmonary Capillary Wedge Pressure, $\mathrm{CO}=$ Cardiac Output.

Resistance is a component of the two-element windkessel model [17] and also remains in the three [11] and four element windkessel models [10]. Together with compliance and impedance, it is one of the three elements on which the RV afterload depends [17]. The pulmonary circulation resistance is significantly lower in comparison with the systemic resistance. It increases in $\mathrm{PAH}$ $[1,3,4]$. The clinical importance of this parameter has been known for a long time. A value above six WE in patients with terminal heart failure and before heart transplantation, is linked to an increased probability of acute right heart failure postoperatively (up to 28 $\%$ in the first three months [18]). For this reason, according to the international Medical Association guidelines, PVR $>6 \mathrm{WE}$ is an exclusion criterion for a heart transplant but not for a combined heart-lung transplant [19]. The value, particularly in the diagnosis and treatment of PAH, is unarguable. Not only is a PVR above three Wood units, a part of the definition [2], but this cut-off value can also be used to distinguish between isolated post-capillary and mixed post- and pre-capillary, pulmonary hypertension [3]. Therefore, according to the most current European guidelines [3], the measurement of PVR is necessary for every right heart catheter examination. In addition, there are signs that, after a point in the natural course of PAH, the rise in PVR becomes steeper [224]. A decrease in PVR is considered an indicator of a patient's hemodynamic improvement $[7,9,14]$, although there is no clear linear correlation with the clinical picture $[14,18]$. 


\section{Water Hammer Phenomenon}

A known phenomenon that occurs in every pump system with rapid change in flow (due to valve opening and closing) is the Water Hammer [25,26]. Water Hammer is a wave of pressure, which due to a rapid change in flow and the resulting changes happen due to start/stop of the pump and opening or closing of a valve. The acute change of state of the pump and/or valve result in a change in momentum (defined as the product of mass $\mathrm{X}$ velocity) of the fluid. This change in momentum produces a shockwave, which under certain circumstances causes damage in the pipes of the pump system. The damage occurs when the applied force of the shockwaves overwhelms the elastic capacity of the pipes. The effects of such a phenomenon are not independent of the geometry of the pipe system. For example, when a water hammer wave reaches a bifurcation or an increase in cross-sectional area, there is a reduction in the amplitude of the wave. With increased resistence (or afterload in terms of hemodynamics) there can be an increase in the amplitude of the reflected wave of the water hammer, especially in systems with a closed end. In general, under certain conditions =water hammer pressure are multiplied [27].

The mathematic equations describing this phenomenon are $[25,26]:$

$$
\frac{\partial u}{\partial x}+\frac{1}{B} \frac{\partial u}{\partial x}=0
$$

and

$$
\frac{\partial u}{\partial x}+\frac{1}{\rho} \frac{\partial u}{\partial x} \frac{f}{2 D} u|u|=0
$$

$\mathrm{u}=$ velocity, $\mathrm{P}=$ pressure, $\mathrm{t}=$ time, $\mathrm{X}=$ space, $\mathrm{f}=$ factor of viscosity $\mathrm{B}=$ module of elasticity, $\rho=$ density.

and the modified equation is

$$
\frac{\partial P}{\partial t}=\rho P W V \frac{\partial V}{\partial t} .
$$

with PWV being pulse wave velocity.

This phenomenon is nothing more than a manifestation of energy transformation from kinetic to dynamic energy due to the different compression ability between the fluid and the pipes of the pump system. The enhanced pressure is transformed in extra compression of the pipe and therefore, a higher initial velocity will produce a more intense compression of the pipe wall. The water hammer phenomenon describes this dynamic change in a close pipe system, when an acceleration or deceleration of the flow occurs. It plays a more significant role in pipe systems with low pressure, such as the pulmonary circulation [21,22].

\section{What Correlations are there Regarding the Pulmonary Circulation?}

The importance of PWV in the evaluation of arterial properties has been demonstrated by several studies: [23] PWV is the most validated method for noninvasively quantifying arterial stiffness. It is regarded as the gold standard due to its simplicity, reproducibility, and clinical relevance [24]. The definition is basically rational: the systolic period produces a pulse that leaves the ventricle and enters the vascular system. Its velocity is the distance between two points of the cycle divided by time [21]. Increased arterial stiffness leads to increased speed of the pulse wave in the artery [22]. PWV is calculated with the Moens-Korteweg form :

$$
\mathrm{PWV}=\sqrt{ }(\mathrm{Eh} / 2 \mathrm{r} \rho)
$$

Eh is Youngs modulus for elasticity (the ratio stress / strain), $r$ is the radius of the vessel (measured in $\mathrm{mm}$ ), $\mathrm{h}$ is the wall thickness (measured in $\mathrm{mm}$ ) and $\rho$ the blood density. A relationship between PWV and compliance (inversely proportional) has also been demonstrated [28-30]. This means that a stiff artery leads the pulse wave much faster compared to an elastic artery. The significance of arterial stiffness is undoubtedly proven. It is an independent risk factor for the development of coronary heart disease (HR 1.23, 95\% CI 1.11 to 1.35), an ischemic stroke (HR 1.28; 95\% CI 1.16 to 1.42) and peripheral arterial disease (HR 1.30, 95\% CI 1.18 to 1.43 ) and has statistical significant correlation with cardiovascular (HR $1.2895 \%$ CI 1.15 to 1.43) and total mortality (HR 1.17, 95\% CI 1.11 to 1.22) [27]. Kaess et al. [28] further investigated the correlation between stiffness and blood pressure and found that although the presence of stiffness is associated with an increased probability of developing hypertension, the development of arterial stiffness remains independent [28].

According to (VII) PWV and the rate of change of pressure of the artery (dp/dt) are proportional Two processes are responsible for this:

a) The elastin and collagen deposits in the extracellular matrix, which shift the power deformation curve ( $F(\lambda)$ curve) to the left [29],

b) And the (particularly in PAH) increased right ventricular stress, which is transmitted into the PA [30].

The presence of the water hammer phenomenon in the arterial system and the human body has been previously mentioned and used. Vennin et al. [31] have accomplished to deliver the aortic pressure from the aortic flow using the above equations and Harald et al [32] have confirmed the measurements in vivo. The mathematic dependency of PWV and $\mathrm{dP} / \mathrm{dt}$ has also been experimentally proven [33-35]. At this point it should be further analyzed which role has the arterial stiffness in the pulmonary circulation. Elasticity is the property that permits the transformation of the wall due to an applied force and by withdrawing of this force the wall returns to its initial shape. This is not the case in the human cardiovascular system, as the arterial walls are not elastic but viscoelastic. This means that a rapid application of force has more loss of energy than a slow one [6]. This is because, a larger rate of change of pressure means greater applied force, which results a greater velocity of stretch and therefore greater viscosity. This increase in viscosity 
means, that a greater energy loss is taking place during the systolic period and that the ventricle must produce a greater energy in order to retain the same stroke volume. Due to the viscoelastic nature of the human arteries, the increased stiffness of the pulmonary artery in patients with pulmonary hypertension the presence of the water hammer cannot be excluded.

\section{What is the Meaning of the Water Hammer in Pulmonary Hypertension?}

The current treatment of PAH can be divided into three levels: General measures, supportive therapy and targeted/specific PAH treatment. General measures should be understood as the avoidance of pregnancy, routine influenza and pneumococcal vaccination, avoiding travel in altitudes over 1500 to $2000 \mathrm{~m}$, psychosomatic, psychological and social patient counselling .The supportive measures include the administration of diuretics for signs of right cardiac decompensation, oxygen therapy at $\mathrm{pO}_{2}<60 \mathrm{mmHg}$ and iron replacement in cases of iron deficiency anemia. Targeted PAH treatment, consisting of endothelin receptor antagonists, phosphodiesterasetype-5 inhibitors, guanylate cyclase stimulators and the prostanoids aim to vasodilatation, increase of the vessel elasticity, reduction of the vascular resistance and improvement of the right ventricular function [36,37]. In engineering however, the treatment of the water hammer cannot be the increase of the pipe elasticity, since the elastic properties of pipes in a given system can no longer be changed and the following methods are used: - The installation of a by-pass pipe with a non-return valve. It does not prevents the water hammer effect, but it can reduce the magnitude of the water hammer wave.

A reduction approximately of 33\% can be achieved [38]. Another alternative is the surge tanks in piping system. These tanks act as a reservoir to suppress the pressure waves and are installed on the discharge pipe. When the pressure in the pipe increases, a dense fluid enters the tank and is stored locally. During periods of subnormal pressure in the pipe, the fluid would flow back to the pipe, preventing rapid velocity changes [38]. Finally, the installation of air chambers. Air chambers are basically a type of high-pressure surge tanks which can be built in small sizes. In these tanks, the pressurized air locates on the top of liquid separately. The size of the chamber must be large enough to compensate the liquid in the subnormal pressure periods [38]. Among water hammer damping devices, air chambers are often used to reduce pressure surges of system to acceptable values. The chamber is more effective if a throttling device is used, resulting in a reduction of the required volume [39]. Although the application of such methods in the human body seems difficult and problematic, a proper use could be an alternative in patients where the medical treatment is no longer sufficient and a transplantation is not a suitable option. Experimental and clinical studies are obviously necessary in order to move in a such direction.

\section{Conclusion}

Water hammer seems to be also manifest in the pulmonary artery of patients with pulmonary arterial hypertension and is already being used in computation of various problems. A deeper understanding may result in newer solutions regarding the treatment of diseases.

\section{References}

1. Humbert M, Stibon O, Chaouat A, Bertocchi M, Habib G, et al. (2006) Pulmonary arterial hypertension in France: Results from a National Registry. Am J Critic Care Med 173: 1023-1030.

2. Hoeper MM, Bogaard HJ, Condliffe R, Frantz R, Khanna D, et al. (2013) Wilkins MR, Badesch DB: Definitions and diagnosis of pulmonary hypertension. J Am Coll Cardiol 62: D42-D50.

3. Galiè N, Humbert M, Vachiery JL, Gibbs S, Lang I, et al. (2015) 2015 ESC/ERS Guidelines for the diagnosis and treatment of pulmonary hypertension. European Heart Journal 37: 67-119.

4. Kovacs G, Berghold A, Scheidl S, Olschewski H (2009) Pulmonary arterial pressure during rest and excersice in healthy subjects. Eur Respir J 34: 888-894.

5. Vachiety JL, Adir Y, Barbara JA, Champion HC, Coglan JG, et al. (2013) Pulmonary hypertension due to left heart disease. J Am Coll Cardiol 62: D100-D108.

6. Westerof N, Stergiopulos N, Noble M (2010) Snapshots of Hemodynamics.

7. Montalescot G, Drobinski G, Meurin P, Maclouf J, Sotirov I, et al. (1998) Effects of prostacyclin on the pulmonary vascular tone and cardiac contractility of patients with pulmonary hypertension secondary to endstage heart failure. Am J Cardiol 82(6): 749-755.

8. Amann Vesti B, Thalhammer C, Kursbuch (2010) DopplerundDuplexsonographie pp. 18-33.

9. Douwes JM, Roofthooft MT, Bartelds B, Talsma MD, Hillege HL, et al. (2013) Pulsatile haemodynamic parameters are predictors of survival in paediatric pulmonary arterial hypertension. Int J Cardiol 168(2): 13701377.

10. Stergiopoulos N, Westerhof BE, Westerhof N (1999) Total arterial inertanceas fourth element of the windkessel model. Am J Phyzsiol 276: H81-H88.

11. Souza R (2008) Assessment of compliancein pulmonary arterial hypertension. European Heart Journal 29: 1603-1604.

12. Randall OS, Van Den Bos GC, Westerhof N (1984) Systemic compliance: does it play a role in the genesis of essential hypertension? Cardiovascular Res 18: 455-462.

13. Loannou CV, Morel DR, Katsamouris AN, Katranitsa S, Startchik I, et al. (2009) Left ventricular hypertrophy induced by reduced aortic compliance. J Vasc Res 46: 417-425.

14. Vonk Noordegraaf A, HaddadF, Chin KM, Forfia PR, Kawut SM, et al. (2013) The Right Ventricle in Pulmonary Hypertension. JACC 62(25): D22-33.

15. Sajan I, Manlhiot C, Reyes J, Mc Crindle BW, Humpl T (2011) Friedberg MK: Pulmonary arterial capacitance in children with idiopathic pulmonary arterial hypertension and pulmonary arterial hypertension associated with congenital heart disease: relation to pulmonary vascular resistance, exercise capacity, and survival. Am Heart J 162(3): 562-568.

16. Kossaify A (2015) Echocardiographic Assessment of the Right Ventricle, from the Conventional Approach to Speckle Tracking and ThreeDimensional Imaging, and Insights into the "Right Way" to Explore the Forgotten Chamber. Clin Med Insights Cardiol 9: 65-75. 
17. Frank O (1899) Die Grundform des arteriellen Pulses. Zeitschrift für Biologie 37: 483-526.

18. Tenderich G, Koerner MM, Stuettgen B, Hornik L, Mirow N, et al. (1998) Does preexisting elevated pulmonary vascular resistance (transpulmonarygradient $>15 \mathrm{~mm} \mathrm{Hg}$ or $>5$ wood) predict early and long-termresults after orthotopic heart transplantation?Transplant Proc 4: 1130-1131.

19. Mehra MR, Canter CE, Hannan MM (2016) The 2016 International Society of Heart Lung Transplantation listing criteria for heart transplantation: a 10-year update. J Heart Lung Transplant 35(1): 1-23.

20. Bshouty Z (2012) Vascular compromise and hemodynamics in pulmonary arterial hypertension: Model predictions. Can Respir J 19(3): 209-215.

21. Laurent S, Cockcroft J, Van Bortel L, Boutouyrie P, Giannattasio C, et al. (2006) Expert consensus document on arterial stiffness: Methodological issues and clinical applications. Eur Heart J 27: 2588-2605.

22. Lee HY, Oh BH (2010) Aging and arterial stiffness. Circ J 74(11): 2257 2262.

23. Stephenson D, Fellow, ASCE (1997) Effects of air valves and pipework on water hammer pressures. ournal of Transportation Engineering pp. 101-106.

24. Kostis JB, Lawrence Nelson J, Ranjan R, Wilson AC, Kostis WJ (2001) Association of increased pulse pressure with the development of heart failure in SHEP. Systolic Hypertension in the Elderly (SHEP) Cooperative Research Group. Am J Hypertens 14: 798-803.

25. Lehmann ED, Parker JR, Hopkins KD, Taylor MG, Gosling RG (1993) Validation and reproducibility of pressure-corrected aortic distensibility measurements using pulse-wave-velocity Doppler ultrasound. J Biomed Eng 15: 221-228.

26. Shirwany NA, Zou MH (2010) Arterial stiffness: a brief review. Acta Pharmacol Sin 31(10): 1267-76.

27. Karras A, Haymann JP, Bozec E, Metzger M, Jacquot C, et al. (2012) Large artery stiffening and remodeling are independently associated with allcause mortality and cardiovascular events in chronic kidney disease. Hypertension 60: 1451-1457.

28. Kaess BM, Rong J, Larson MG, Hamburg NM, Vita JA, et al. (2012) Aortic stiffness, blood pressure progression, and incident hypertension. JAMA 308: 875-881.

29. Hunter KS, Albietz JA, Lee PF, Lanning CJ, Lammers SR, et al. (2010) Invivo measurement of proximal pulmonary artery elastic modulus in the

\section{ISSN: 2574-1241}

DOI: $10.26717 /$ BJSTR.2019.23.003890

Sinanis T. Biomed J Sci \& Tech Res

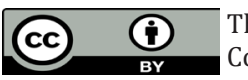

This work is licensed under Creative Commons Attribution 4.0 License

Submission Link: https://biomedres.us/submit-manuscript.php neonatal calf model of pulmonary hypertension: Development and exvivo validation. J Appl Physiol 108(4): 968-975.

30. Lammers S, Scott D, Hunter K, Tan W, Shandas R, et al. (2012) Mechanics and Function of the Pulmonary Vasculature: Implications for Pulmonary Vascular Disease and Right Ventricular Function. Compr Physiol 2(1): 295-319.

31. Vennin S, Mayer A, Li Y, Fok H, Clapp B, et al. (2015) Noninvasive calculation of the aortic blood pressure waveform from the flow velocity waveform: a proof of concept. Am J Physiol Heart Circ Physiol 309(5): H969-H976.

32. Harada A, Okada T, Niki K, Chang D, Sugawara M (2002) On-line noninvasive one-point measurements of pulse wave velocity. Heart Vessels 17(2): 61-68.

33. Shizuo Hanya (2013) Validity of the Water Hammer Formula for Determining Regional Aortic Pulse Wave Velocity: Comparison of OnePoint and Two-Point (Foot-to-Foot) Measurements Using a Multisensor Catheter in Human. Ann Vasc Dis 6(2): 150-158.

34. Khir AW, OBrien A, Gibbs JS, Parker KH (2001) Determination of wave speed and wave separation in the arteries. J Biomech 34(9): 1145-1155.

35. Rakebrandt F, Palombo C, Swampillai J, Schön F, Donald A, et al. (2009) Arterial wave intensity and ventricular-arterial coupling by vascular ultrasound: rationale and methods for the automated analysis of forwards and backwards running waves. Ultrasound Med Biol 35(2): 266-277.

36. Galiè N, Olschewski H, Oudiz RJ, Torres F, Frost A, et al. (2008) Ambrisentan in Pulmonary Arterial Hypertension, Randomized, DoubleBlind, Placebo-Controlled, Multicenter, Efficacy Studies (ARIES) Group. Ambrisentan for the treatment of pulmonary arterial hypertension: results of the ambrisentan in pulmonary arterial hypertension, randomized, double-blind, placebo-controlled, multicenter, efficacy (ARIES) study 1 and 2. Circulation 117(23): 3010-3019.

37. Galiè N, Rubin LJ, Hoeper M, Jansa P, Al Hiti H, et al. (2008) Treatment of patients with mildly symptomatic pulmonary arterial hypertension with bosentan (EARLY study): a double-blind, randomized controlled trial. Lancet 371: 2093-2100.

38. Tan Wee Choon, Lim Kheng Aik, Lim Eng Aik, Teoh Thean Hin (2012) Investigation of Water Hammer Effect Through Pipeline System. International Journal on Advanced Science Engineering Information Technology

39. Martino G, Fontana N (2012) Simplified Approach for the Optimal Sizing of Trottled Air Chambers. Journal of Hydraulic Engineering pp. 11011109.

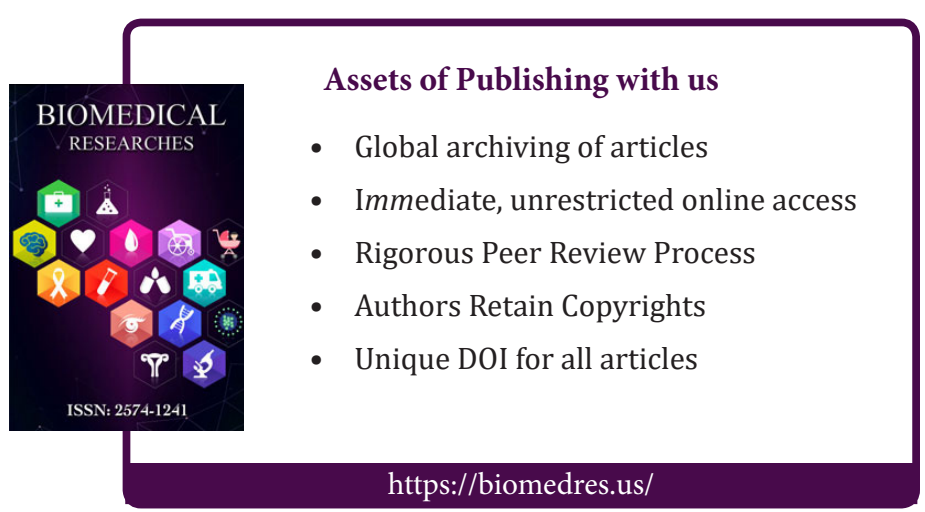

